\title{
Utility Impact Assessment of Road Projects in the State of Qatar
}

\author{
Mohammad Mujtaba Hamidy \\ mhamidy@mme.gov.qa \\ Ministry of Municipality and Environment, Doha, Qatar
}

\begin{abstract}
Qatar has been blessed with large reserves of natural gas and since the past 20 years its leaders have been busy formulating its path to modernization. Henceforth, the sovereign state has been and is still going through tremendous development phase to meet the 2030 vision of making Qatar a world class country and giving its citizens a very high standard of living. This is to be achieved with development in key sectors namely economic, social, environmental and more importantly human development. Moreover, in 2010 Qatar was awarded to host the 2022 FIFA World Cup, which increased the country's pipeline of projects such as stadia, hotels, metro and ports (air and sea). This also led to fast tracking of its stockpile of existing infrastructure projects to meet 2022 deadlines. Accordingly, significant portion of these projects will be constructed within the right of way or road reserve. Although the current practice of road construction and utility installation in Qatar is in-line with world best practices, but such practices were not followed stringently in the past. Moreover, Qatar's cities have gone through an excessive urban densification, which meant that the service providers had to provide greater number of utilities and road authorities had to design and construct complex road networks that involved tunnels, bridges, underpasses and overpasses. These challenges are further compounded by the fact that there are narrow right of ways for the installation of all these utilities in the urban areas. In tackling these challenges, the Ministry of Municipality and Environment (MME) along with road authorities and utility providers have gone through robust review and modification of their practices. As a result, actions were taken and in particular MME developed a process namely, utility impact assessment process that guides the road designers to collaborate with utility designers to achieve a more value engineered outcome.
\end{abstract}

Keywords: Right of way; Subsurface utilities; Value engineering

\section{INTRODUCTION}

Qatar is going through an unprecedented development rate that is comparable to some of the major cities that have gone through modernization in recent times and are still going through such as Shanghai and Goughaze. With numerous projects under construction, tender and design also significant portion of projects in the pipeline. It has been reported that \$US200 plus billions is being invested in the country's development and with such colossal investment it will naturally lead to tremendous challenges across all governmental sectors, and subsequently it will be a great opportunity for the private sector to embark.

The main driver for this infrastructure development has been Qatar's 2030 Vision that entails modernization of the State across all sectors. However, in this paper we will 
focus on the upgrade of road network and more importantly the utility services that are installed below the road networks. At present the traffic volume for the capacity of the road network is excessive, especially in inner urban areas of Doha, which is reflected in the daily commute of the residents. If we compare the infrastructure network to the human circulatory system, highways and roads function as the delivery system, transporting services from one location to another just like the arteries, veins and capillaries that transport nutrients to all parts of the body with the flow of blood. Just like a healthy body requires a healthy circulatory system, so does a healthy city or country require a healthy and smooth-running infrastructure network. The country's decision makers are fully aware of the situation and are taking all the necessary measures not to aggravate the problem further. Hence, a major surgical operation worth \$US200 billion plus is planned to make Qatar a world class city comparable to the world's best cities in terms of infrastructure.

\section{RIGHT OF WAY CHALLENGES}

Right of way or road reserve is generally the space that allows the movement of vehicular traffic as well as non-vehicular traffic (including train, tram, pedestrian, cycle etc... and their associated facilities and appurtenances). The right of way does not only act as a conduit for the movement of traffic but also as a medium to interconnect and deliver all the necessary amenities such as water, electricity, ICT, security and sanitation services to the residents, businesses, institutions and the likes to make the town, city and the entire country function. However, one of the biggest challenges that Qatar is facing is lack of availability of space/corridors for utilities.

The current practice in Qatar is that all utilities in urban areas must be located underground. This is in line with best global standards similar to most advanced cities of the world. At present the standard in Qatar is that each of the utilities have been designated a specific corridor/space within the right of way, whereby the shallower utilities have been located in the edges of the right of way and the deeper utilities (gravity driven) is located more centrally in the road carriageway. If this standard gets enforced and implemented it will lead to an ideal situation. However, such standard was not stringently followed, and utilities were installed within the right of way in a haphazard manner.

To outline some of the challenges it must highlighted that in addition to excessive traffic, the road right of way is extremely congested with subsurface utilities throughout Doha. As a result of proposed road improvements to cater for the greater volume of traffic, the carriageways (vehicle carrying segment of the right of way) will be widened to accommodate greater volume of vehicle movement. With the exception of the deep gravity related pipes, the rest of the utilities are generally placed at the verges of the road and not under the pavements for ease of construction as well as to maintain easy access for operation and maintenance. Given the constraints posed by the road widening the non-gravity utility such as telecommunication ducts, pressured water pipes and electricity ducts will inevitably fall inside the paved roadway, a practice generally not recommended by the respective authorities, due to difficulty in gaining access. In addition, the proposed road configuration is made up of complex set of arrangements at the junctions that may consist of tunnels, underpasses, bridges and flyovers to cater for 
free-flowing traffic. This results in installation of utilities at the junctions to be more convoluted as the availability of accessible space for utilities is significantly reduced.

\subsection{Overcoming Challenges}

To overcome challenges, the State of Qatar has taken number of initiatives and each service agency has developed and modified their procurement process. One of the key organizations in the country is the Infrastructure Planning Department (IPD) of Ministry of Municipality and Environment (MME), whose is responsible to arrange the placement of utilities within a right of way and allot the necessary space for all the services. To carry this work, number of initiatives were introduced that considered the planning and design stages of the project as well the delivery of the project. Furthermore, it must be noted that the urban planning of Qatar is carried out by the Ministry of Municipality and Environment as well, where assigning the land use directly influences and correlates to the space and corridor allocation for the utilities within a given right of way.

The Infrastructure Planning Department of MME has created a flow chart titled "MMUP utility investigation approval procedure". This flow chart enables all the road authorities working on the road project to clearly see the flow of work during the planning and design development of the project. This flow chart can be broken into three major components, namely, "investigation", "assessment" and "approval", as per Figure 1 below.

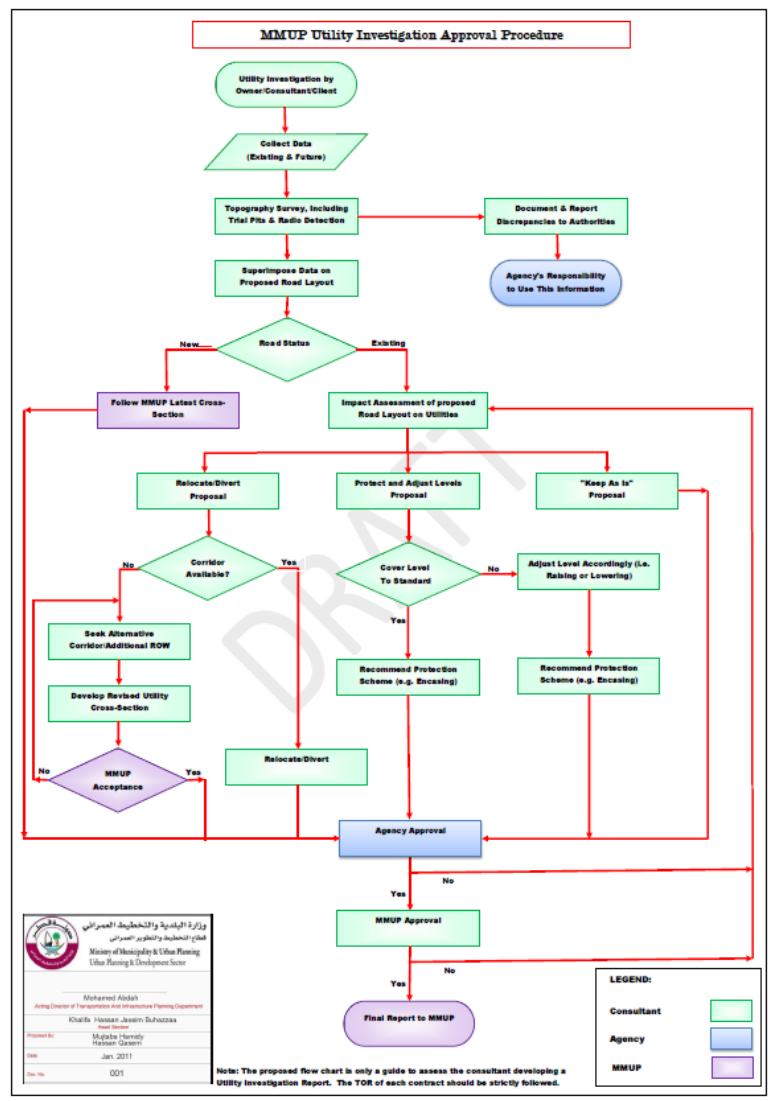

Figure 1: Flow chart for the MMUP utility investigation approval procedure 


\subsection{Investigation}

First let us consider the investigation component. Once the extent of the road project has been defined by the project proponent, usually Public Works Authority (Ashghal) or Ministry of Transportation and Communication (MoTC), then the first essential aspect of the project is to establish an accurate base for the project. Just like traffic engineer carrying a "traffic survey" to capture the existing flow of traffic and in addition obtains the necessary future land-use of the area to establish the future projections of traffic flow, similarly the utility engineer of the project must obtain the latest information for all the utilities. This includes an accurate as built information of the all the existing utilities within the subject road design as well as proposed utility plans. Upon receipt of all the agencies' As Built information it is essential that the responsible engineer engages a licensed surveyor to carry an onsite investigation to verify the location of the agencies As Built information.

It must be emphasized that number of studies and best practices around the world indicate that obtaining accurate As Built information is vital in developing and delivering the most cost effective, timely and less disruptive project. Accordingly, most of the departments of Transportation in US adopt Subsurface Utility Engineering (SUE), which is a well established engineering practice that looks at different stages of the project with different levels of accuracy of the existing assets. This accuracy or perhaps the quality of the information ranges between D to A, where Quality D is desktop information while Quality A involves detailed onsite investigation determining the precise location of the asset's both in XY Cartesian as well in its vertical component.

Given that there is overwhelming number of road and infrastructure projects in Qatar it was IPD-MME's judgement that adoption of SUE practices would've not been practical to incorporate for Qatar's road projects. However, given that the determination of accurate information plays a vital role, carrying adequate field investigation through topographic survey as well more advance form of survey techniques such as radio detection as well as ground penetrating radar and other similar advanced techniques that ascertains an accurate location of below surface utilities were required to be applied. In short MME-IPD encourages the principles of SUE and enforces wherever possible that engineers make appropriate level of analysis on the topographic survey obtained to validate the accuracy of the As Built information. This is achieved through overlaying the As Built information with the surfaced features obtained from the topographic surveys such as manholes, vents, valves, gullies etc...

After the comparison has taken place any the discrepancy between the two set of data is determined, it is the duty of the engineers to report all the inaccurate field data to their respective agency and accordingly the engineer must use the more accurate information of the on-site investigation in developing the design and assessment of the project.

\subsection{Impact Assessment}

Upon obtaining accurate information the engineer can confidently commence the impact assessment of the proposed road on the existing utilities as well as any future utilities along the subject right of way. How existing and proposed utilities are impacted primarily depend on the actual road design. It must be noted that as part of Public Works Authority (the implementation authority responsible for road and drainage) road 
projects, there are two different road programmes, namely the "local road and drainage programme" and the "expressway programme". The general aim of local roads project is to resurface, road widening, improve drainage, allocation of footpath and lighting as well adjustment and installation of the subsurface utilities. However, expressway roads generally take a more extensive design especially around the junction that may include multilevel interchanges which include underpasses, tunnels, ramps and bridges to allow for the free-flowing of traffic movement, in addition there is also metro network and large gravity mains. In carrying the impact assessment of these schemes, the utility and road designers need to make the determination of how the existing utilities will be impacted i.e. for each of the existing utility the design engineer generally has the following main decision to make:

- Keep it in its current location with no adjustment.

- Protect, lower or raise it to meet agency's requirements.

- Or relocate to a more suitable location.

\subsubsection{Value engineering the road and utility arrangement}

A value engineering exercise needs to be carried out. MME supports proposals that keeps utilities in their existing location as much as possible by adjusting or providing provisions within the road design such as:

i Adjusting the road geometry.

ii Modifying the highway drainage.

iii Appropriate retaining walls selection and design.

iv Appropriate design of batters/slopes/barriers and abutment arrangements to minimize adjustment of existing utilities.

$\mathrm{v}$ Protection above water pipes in the proposed paved areas (carriageway or carpark).

vi Concrete protection above electric cables and other ducts (e.g. telecommunication and security ducts).

vii Departures from standard design specifications for road design as well as utility design.

viii Road carriageway or lane width reduction.

ix Consider signal standard changes.

$\mathrm{x}$ Increased signal mast arm lengths.

xi Adjust the signal and sign locations.

It is also important that the engineer needs to future proof the construction of the road, where future utilities should be catered for, accordingly it is important that all the planned utilities are incorporated as part of the proposed road project. Therefore a comprehensive utility infrastructure project will be built, the benefit of such practice is cost saving to all the parties where subsurface utilities are placed prior to the pavement construction, which in-turn will not necessitate future road opening (pavement cut), further disruption to the travelling public and subsequently this will decrease the longevity of the road network. Presently, a lot of collaboration between agencies has been carried out to achieve a high-level agreement between road authority and utility agencies that incorporates the utility agencies' future work into the proposed road project. However, such practices are happening only in selected projects and not across all the road projects. However, a more comprehensive agreement can be easily achieved 
given that most utility agencies are government owned and the budget for all the projects in Qatar comes from the same source (Ministry of Finance). Accordingly all the parties have vested interests to coordinate their work to obtain the most cost effective result that will also be delivered much more efficiently with better quality and that will last much longer.

\subsubsection{Installation of utilities in narrow corridor}

One of the key constraints in State of Qatar is the availability of right of way, as the existing right of ways are narrow and acquisition of land in Doha is very expensive and not desirable as it causes significant disruption to the public and potential loss of historical value of the city. Accordingly, the utility engineer must develop out of the box solutions to allow all the utilities to be placed in narrow corridor. To carry out these exceptional designs MME provides some design guides to allow the designer to be more creative to achieve nonstandard solutions. These guidelines include:

i The width of the corridors for utilities shall be reduced and shall only be provided for existing and known future utilities.

ii Greater number of utilities shall be placed under the pavement such as transmission pipes and cables.

iii Shared trenches/common trench for compatible utilities e.g. gas and water.

iv Stacking of utilities over short stretches e.g. transmission cables \& large diameter pressure mains below distribution cables $\&$ smaller diameter pressure mains.

$\mathrm{v}$ Telecommunication ducts above pressure mains or transmission cables where concrete slab is placed between the two for protection.

vi Easement, instead of acquiring land - utility easement can be created to allow utilities to traverse at pinch points.

vii Rerouting of the utilities within secondary minor roads parallel to main traffic routes, this option should be especially considered at junctions.

viii Consideration should be made for power galleries or utility tunnels in lieu of land acquisition and when other options have been exhausted and value engineering has identified tunnels to be an optimal solution in a given case.

\subsubsection{Approval process}

Upon investigation and assessment of the utilities the project proponent or their assigned consultant must submit appropriate documentation to MME. The approval process of the project prior to implementation is carried out in three stages (i.e. first MME initial approval, second Agencies approval, third MME's pre-construction approval). The first critical stage of the approval involves the corridor allocation for the existing and proposed utilities within the given right of way. This stage requires the approval of MME as the width of the right of way to accommodate the road and utility component of the project solely depends on MME's discretion, whereby MME has to consider that the land acquisition of the project is fully justified for the road elements as well as utilities. Hence once the width of the right of way has been established the approval of how the right of way should be divided among the utilities also lies within MME.

Upon receipt of MME's first initial approval the project proponent must seek NOCs from utility providers. The project proponent is also required to meet agencies' conditions 
and all their requirements. Any disagreement or point of contingency between the project proponent and a utility agency should be raised to MME for resolution.

The final stage of approval prior to the implementation of the project is once again with MME where the project proponent must submit all the agencies' approval and if there are any changes in comparison to MME's initial approval, those must be highlighted and documents must be provided to fully justify the proposed changes.

Once the project has been constructed in order to certify and commission the project, MME will also require a completion certificate from the relevant authorities and a copy of the "As Built". The As built plans will be checked against the pre-construction approved documents and in case of any discrepancy between the two submittals, the project proponent is required to provide clarification and justification. If accepted, MME will issue a final approval which will allow the project proponent to request final completion certificate from the concerned municipality.

\section{CONCLUSION}

In conclusion, Qatar will go through an extraordinary development phase in the coming decade and majority of the projects will involve the improvement of the current right of ways for much needed and improved traffic flow. The improvement of the road will impact the subsurface utilities and will require proper assessment. The high demand for utilities to service a high density development coupled with narrow right of way as well as complex road arrangement, poses a great challenge for all the road, highway and utility engineers to develop an innovative and cost effective solution for the country to function smoothly at its best. MME, Public Works Authority and all the utility agencies have made significant improvements in coordinating, collaborating and communicating across all the ongoing development projects to achieve the desired outcome of building a world class infrastructure for State of Qatar. MME has taken the lead to apply the best practices in optimizing the existing right of ways, through guiding engineers to design and develop a more innovative solutions to overcome the right of way challenges as well as streamlining the overall approval process to fast track the delivery of these projects.

\section{REFERENCES}

Avoiding Utility Relocation (2002). US Department of Transportation Federal Highway Administration, Washington D. C. Access on Sept 10, 2019 [Online], Available: http://www. dot.ga.gov/PartnerSmart/utilities/Documents/AvoidingUTLRelocations.pdf.

Cesar, Q., Yingfeng (Eric), Edgar, K. \& Le, Jerry (2010). Optimizing Utility Owner Participation in the Project Development and Delivery Process, National Technical Information Service, Austin, 161 pages. Available: https://pdfs.semanticscholar.org/0f12/ aef23d6f0ede89bcbee346b5407e5730ca1f.pdf

Identification of Utility Conflicts and Solutions (2012). The National Academies of Science Engineering Medicine, Washington D. C, 2009. Accessed on Oct 3, 2019 [Online]. Available: https://www.nap.edu/catalog/22819/identification-of-utility-conflicts-and-solutions.

Integrating the Priorities of Transportation Agencies and Utility Companies (2009). The National Academies of Science Engineering Medicine, Washington D. C. Access on Oct 3, 2019 [Online]. Available: https://www.nap.edu/catalog/23037/integrating-the-priorities-of-transporta- 
tion-agencies-and-utility-companies.

Monri, H. (2015). A Survey of Utility Coordination Practices in the Toronto Area. Paper of the 2015 Conference of the Transportation Association of Canada Charlottetown, PEI, pages, 19. Available: http://conf.tac-atc.ca/english/annualconference/tac2015/s23/monri.pdf.

Raymond, S. (1994). Indirect Costs of Utility Placement and Repair Beneath Streets, National Technical Information Service, Minnesota, 56 pages. Available: http://apps.fcc.gov/ecfs/ document/view; ECFSSESSION=h00vW0yTFGc9X2SnzkXvxt14R2P2H1vrp2TNvQR0nmhyZzT520RC! $1503707191 ! 1967462809 ? \mathrm{id}=6009552992$

U.S Domestic Scan Program (2006). Best Practices in Right of Way Acquisition and Utility Relocation. National Cooperative Highway Research Program Transportation Research Board, Cambridge. Access on Oct 3, 2019 [Online]. Available: http://www.trb.org/Main/ Blurbs/158478.aspx

Urban Planning Council, Abu Dhabi (2013). Abu Dhabi Utility Corridors Design Manual. Access on 5 Oct 2019 [Online]. Available: https:/www.upc.gov.ae/en/-/media/upc/feature/tools/ ucdm_version-1-en/compressed_ucdm_english.ashx.

Utility Accommodation Policy and Standard (2016) (Revised 01/12/2018). Georgia Department of Transport, 2018 Access: Oct 12019 [Online]. Available:http://www.dot.ga.gov/PartnerSmart/ utilities/Documents/2016_UAM.pdf

Utility Coordination Manual of Instruction (2017). Utah Department of Transportation, Salt Lake City. Access on Sept 7, 2019 [Online]. Available: https:/www.udot.utah.gov/main/ uconowner.gf?n=2989808693862464

Utility Investigation Best Practices and Effects on TxDOT Highway Improvement Projects (2013). Texas Department of Transport and the Federal Highway Administration, Austin. Access on 4 Oct 2019 [Online]. Available: http://tti.tamu.edu/documents/0-6631-1.pdf

Utility Relocation and Accommodation on Federal-Aid Highway Projects (2003). Sixth Ed, Office of Program administration Federal Highway Administration, Washington D. C, Access on Sept 10, 2019 [Online]. Available: https://www.fhwa.dot.gov/reports/utilguid/

Utility Policy Manual Ministry of Transportation and Highways, British Columbia, 1995, Access on 5 Oct 2019 [Online]. Available: http://www.th.gov.bc.ca/permits/Utility\%20Permit\%20 Manual.pdf 